\title{
PERANCANGAN LEMARI PENGERING PAKAIAN YANG ERGONOMIS DI LAUNDRY SI DOEL BATU
}

\author{
Sumanto ${ }^{1)}$, Sentot Achmadi ${ }^{2)}$, Ali Mahmudi ${ }^{3)}$ \\ 1) Prodi Teknik Industri S1 ITN Malang \\ ${ }^{2,3)}$ Prodi Teknik Informatika S1 ITN Malang \\ Email : sumanto@ lecturer.itn.ac.id
}

\begin{abstract}
Abstrak, Sumber energi terbesar di bumi ini adalah matahari. Tidak ada kehidupan di bumi ini jika tidak ada matahari. Ketergantungan kehidupan manusia di segala bidang kehidupan terhadap matahari tidak dapat dihindari. Salah satu ketergantungan manusia terhadap energi matahari adalah proses pengeringan pakaian yang telah dicuci. Pemanfaatan sinar matahari untuk pengeringan pakaian kadang terkendala dengan musim. Ketika musim penghujan, hampir setiap hari sinar matahari terhalang awan, sehingga tidak dapat menjangkau bumi. Kondisi seperti ini kerap merugikan para pelaku usaha laundry. Untuk mengatasi hal ini perlu dirancang sebuah alat pengering yang didesain secara ergonomis untuk mengeringkan pakaian setelah dicuci dengan memanfaatkan panas buangan dari air conditioner (AC). Hasil rancangan berdasarkan data antropometri adalah sebuah lemari/cabinet pengering dengan dimensi tinggi $92 \mathrm{~cm}$, lebar $60 \mathrm{~cm}$ dan panjang $55 \mathrm{~cm}$. Data untuk menentukan efisiensi alat adalah menimbang massa pakaian yang telah dicuci dan dikeringkan dengan mesin cuci dan dimasukkan ke dalam lemari pengering. Selama proses pengeringan panas buangan dari AC dimasukkan ke dalam lemari pengering. Setelah selang waktu10 menit pakaian diangkat dan ditimbang massanya kembali. Laju pengurangan air dihitung dengan selisih massa pakaian dibagi dengan selang waktu yang diperlukan. Hasil pengeringan dengan lemari pengering dibandingkan denagn hasil pengeringan alami untuk menentukan efisiensi alat. Hasil uji coba alat menunjukkan efisiensi laju pengurangan kadar air dalam pakaian dibandingkan dengan pengeringan alami dengan cuaca mendung pakaian adalah sebagai berikut: (1) Handuk 64,15\%, (2) Baju 188,10\%, (3) Kaos tebal $113,56 \%$ dan (4) Kaos tipis $155,00 \%$.
\end{abstract}

Kata Kunci: lemari, pengering, ergonomi

\section{PENDAHULUAN}

Sumber energi terbesar di bumi ini adalah matahari. Tidak ada kehidupan di bumi ini jika tidak ada matahari. Ketergantungan kehidupan manusia di segala bidang kehidupan terhadap matahari tidak dapat dihindari. Salah satu ketergantungan manusia terhadap energi matahari adalah proses pengeringan pakaian yang telah dicuci. Pemanfaatan sinar matahari untuk pengeringan pakaian kadang terkendala dengan musim. Ketika musim penghujan, hampir setiap hari sinar matahari terhalang awan, sehingga tidak dapat menjangkau bumi. Kondisi seperti ini kerap merugikan para pelaku usaha laundry. Demikian juga yang dialami oleh Laundry Si Doel.

Volume pekerjaan yang berhasil diselesaikan lebih banyak pada musim kemarau, hal ini dikarenakan pakaian yang selesai dicuci dijemur di bawah terik matahari. Jika matahari bersinar dengan teriknya, maka pakaian akan lebih cepat kering, begitu pula sebaliknya jika mendung/turun hujan maka pakaian lebih lama keringnya.
Pelaku usaha Laundry Si Doel mencoba menyelesaikan permasalahan ini dengan memberikan panas yang berasal dari lampu 100 Watt yang dipasang di atas jemuran pakaian. Hal ini tidak efektif dikarenakan panas dari lampu tersebar ke segala arah dan sebagian besar terbuang sia-sia.

Yacobus Damar Alit (2016), melakukan penelitian yang merancang mesin pengering pakaian tertutup dengan menggunakan elemen pemanas 1711 Watt. Hasil penelitiannya adalah pakaian sebanyak 15 potong yang diperas dengan mesin cuci dan dikeringkan dengan mesin dalam waktu 50 menit, sedangkan untuk sejumlah 20 potong dapat dikeringkan dalam waktu 60 menit. Hasil penelitian ini cukup efektif dalam proses pengeringan pakaian, tetapi kelemahan dari mesin ini adalah penggunaan daya yang sangat besar hingga mencapai 1711 Watt, padahal listrik yang terpasang di pelaku usaha ini hanya 1300 Watt.

Andar Heryanto (2018), dalam penelitiannya yang melakukan pengujian variasi massa pada lemari pengering pakaian portable sistem hibrida dengan menggunakan panas 
buang kondensor AC split 1 PK diperoleh hasil laju pengeringan pada pengujian massa adalah $0,1303-0,6468 \mathrm{~kg} / \mathrm{jam}$. Kelemahan dari penelitian ini belum menyentuh aspek ergonomi.

Penggunaan mesin pengering pada usaha laundry ini belum ada, sehingga perlu dirancang mesin pengering yang ergonomis agar pengguna mesin tersebut tidak mengalami kelelahan. Perancangan mesin pengering ini berupa lemari pengering pakaian yang didasarkan pada prinsip ergonomis dengan memanfaatkan panas buangan AC portable sebagai sumber energi panasnya.

Ketika cuaca mendung, biasanya udara di dalam rumah terasa lebih panas ditambah lagi dengan aktivitas setrika yang menambah panas dalam ruangan. Sehubungan dengan hal ini pelaku usaha laundry ini menyalakan AC portabel untuk menyejukkan ruangannya.

Proses AC menghasilkan udara dingin/sejuk diikuti dengan dihasilkannya panas buangan. Panas buangan ini dapat dimanfaatkan sebagai sumber panas bagi lemari pengering pakaian yang akan dirancang. Dengan proses ini maka panas buangan AC yang seharusnya terbuang sia-sia dapat dimanfaatkan untuk mengeringkan pakaian setelah dicuci dan diperas dengan mesin cuci.

\section{Air Conditioner (AC)}

AC merupakan suatu alat yang digunakan untuk mengkondisikan udara. Kondisi yang dijaga oleh AC adalah suhu udara. Orang menggunakan $\mathrm{AC}$ untuk menyejukkan bahkan mendinginkan suhu udara yang panas.

Secara umum jenis AC ada dua macam, (1) AC portabel yang dapat dipindah-pindahkan dan (2) AC permanen yang dipasang pada tempat tertentu. berikut:

Cara kerja AC digambarkan sebagai

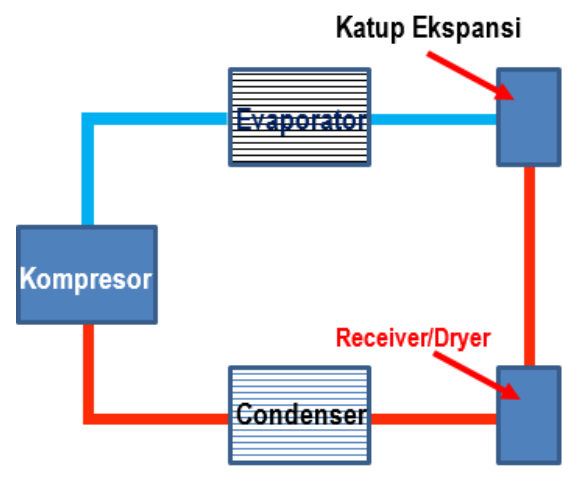

Gambar 1. Gambaran komponen-komponen AC
Kompresor dalam sistem pendinginan berfungsi memberikan tekanan pada fluida (refrigent) yang masuk ke dalam condenser. Karena tekanan yang tinggi maka fluida di dalam condenser termampatkan, sehingga berubah fase dari uap menjadi cair. Karena proses perubahan uap menjadi cair dilakukan dengan melepas kalor, maka pada condenser inilah panas dari AC dibuang.

Kemudian fluida dialirkan menuju katup ekspansi. Di dalam katup ekspansi ini tekanan fluida diturunkan, sehingga fluida kembali menjadi uap (berubah fase dari air menjadi uap). Fluida yang telah menjadi uap ini diteruskan menuju evaporator. Di dalam evaporator tekanan fluida menjadi lebih rendah, sehingga perubahan fase cair menjadi uap menjadi lebih sempurna. Karena proses penguapan membutuhkan panas, maka panas dari ruangan diambil untuk proses perubahan fase di evaporator. Jadi pada evaporator inilah udara dingin dari AC dihembuskan oleh blower. Setelah itu fluida masuk ke dalam kompresor dan mengalami proses yang sama secara terus menerus.

\section{Proses Pengeringan Pakaian}

Pakaian yang dicuci akan menjadi basah karena air memiliki gaya adesi lebih besar daripada gaya kohesi. Gaya adesi adalah gaya tarik antara molekul air dengan pakaian, sedangkan gaya kohesi air adalah gaya tarik antar partikel/molekul air.

Ketika pakaian basah diberikan panas secara terus menerus, maka suhu molekulmolekul air pada pakaian meningkat. Peningkatan suhu molekul air mengakibatkan molekul air mengalami gerakan-gerakan yang menghasilkan energi kinetik yang melawan gaya kohesif dan adesif, sehingga molekul-molekul air melepaskan ikatannya antar molekul air dan juga melepaskan diri dari kain.

Pada temperatur tertentu air mulai mengalami penguapan secara terus-menerus yang pada akhirnya molekul-molekul air tidak ada lagi pada pakaian. Hasilnya adalah pakaian kering.

\section{Ergonomi}

Menurut Tarwaka dkk (2004), "Ergonomi adalah ilmu, seni dan penerapan teknologi untuk menyerasikan atau menyeimbangkan antara segala fasilitas yang digunakan baik dalam beraktivitas maupun istirahat dengan 
kemampuan dan keterbatasan manusia, baik fisik maupun mental, sehingga kualitas hidup secara keseluruhan menjadi lebih baik".

\section{- Tujuan Ergonomi}

Secara umum tujuan dari penerapan ergonomi adalah: (1) Meningkatkan kesejahteraan fisik dan mental melalui upaya pencegahan cedera dan penyakit akibat kerja, menurunkan beban kerja fisik dan mental, mengupayakan promosi dan kepuasan kerja. (2) Meningkatkan kesejahteraan sosial melalui peningkatan kualitas kontak sosial, mengelola dan mengkoordinir kerja secara tepat guna dan meningkatkan jaminan sosial baik selama kurun waktu usia produktif maupun setelah tidak produktif. (3) Menciptakan keseimbangan rasional antara berbagai aspek, yaitu aspek teknis, ekonomis, antropologis dan budaya dari setiap sistem kerja yang dilakukan, sehingga tercipta kualitas kerja dan kualitas hidup yang tinggi.

\section{- Kapasitas Kerja}

Untuk mencapai tujuan ergonomi, maka beberapa faktor perlu diperhatikan dalam rangka menciptakan keserasian antara pekerja dengan pekerjaannya. Beberapa faktor yang perlu diperhatikan adalah sebagai berikut:

\section{Umur}

Kemampuan melakukan kerja antar golongan umur berbeda. Orang muda dan orang tua dalam hal penglihatan, pendengaran, pengambilan keputusan akan berbeda. Oleh karena itu pengaruh umur dapat dijadikan salah satu pertimbangan dalam pemberian pekerjaan.

2. Jenis Kelamin

Kekuatan fisik antara wanita dan pria berbeda. Kekuatan wanita hanya 2/3 kekuatan pria, sehingga kapasitas kerja antara wanita dan pria mestinya dibedakan.

3. Antropometri

Data antropometri sangat penting dalam menentukan alat dan cara mengoperasikannya. Kesesuaian hubungan antara antropometri pekerja dengan alat yang digunakan sangat berpengaruh pada sikap kerja, tingkat kelelahan, kemampuan kerja dan produktivitas kerja.
5. Kesehatan dan Nutrisi

Status kesehatan dan nutrisi atau keadaan gizi berhubungan erat satu sama lainnya dan berpengaruh pada produktivitas dan efisiensi kerja. Dalam melakukan pekerjaan tubuh memerlukan energi, apabila kekurangan baik secara kuantitatif maupun kualitatif kapasitas kerja akan terganggu. Perlu keseimbangan antara in-take energi dan output yang harus dikeluarkan. Nutrisi yang kuat saja tidak cukup, tetapi diperlukan adanya tubuh yang sehat agar nutrisi dapat dicerna dan didistribusikan oleh organ tubuh.

6. Kesegaran Jasmani

Hairy (1989) dan Hopkins (2002) dalam Tarwaka (2004), menyatakan bahwa kesegaran jasmani adalah suatu kesanggupan atau kemampuan dari tubuh manusia untuk melakukan penyesuaian atau adaptasi terhadap beban fisik yang dihadapi tanpa menimbulkan kelelahan yang berarti dan masih memiliki kapasitas cadangan untuk melakukan aktivitas berikutnya

7. Kemampuan Kerja Fisik

Kemampuan kerja fisik adalah suatu kemampuan fungsional seseorang untuk mampu melakukan pekerjaan tertentu yang memerlukan aktivitas otot pada periode waktu tertentu. Lamanya waktu aktivitas dapat bervariasi antara beberapa detik (untuk pekerjaan yang memerlukan kekuatan) sampai beberapa jam (untuk pekerjaan yang memerlukan ketahanan). Menurut Hairy (1989) dan Genaidy (1996) dalam Tarwaka (2004), bahwa komponen kemampuan kerja fisik dan kesegaran jasmani seseorang ditentukan oleh kekuatan otot, ketahanan otot dan ketahanan kardiovaskuler.

\section{- Antropometri}

Antropometri berasal dari "anthro" yang memiliki arti manusia dan "metri" yang memiliki arti ukuran. Antropometri adalah sebuah studi tentang pengukuran tubuh dimensi manusia dari tulang, otot dan jaringan adiposa atau lemak (Survey, 2009). Menurut (Wignjosoebroto, 2008), antropometri adalah studi yang berkaitan dengan pengukuran dimensi tubuh manusia. Bidang antropometri meliputi berbagai 
ukuran tubuh manusia seperti berat badan, posisi ketika berdiri, ketika merentangkan tangan, lingkar tubuh, panjang tungkai, dan sebagainya.

Manusia memiliki berbagai ukuran tubuh manusia yang berbeda antara manusia yang satu dengan lainnya, seperti berat badan (kurus, sedang, dan berat), ukuran tinggi tubuh ketika posisi berdiri (kecil, sedang, dan tinggi), lingkar tubuh (kecil, sedang, dan besar) serta posisi ketika merentangkan tangan, panjang tungkai, dan sebagainya. Data antropometri tersebut digunakan untuk berbagai keperluan, seperti perancangan stasiun kerja, fasilitas kerja, dan desain produk agar diperoleh ukuran-ukuran yang sesuai dan layak dengan dimensi anggota tubuh manusia yang akan menggunakannnya.

Persentil adalah suatu nilai yang menunjukkan persentase tertentu dari orang yang memiliki ukuran pada atau di bawah nilai tersebut. Persentil pada dasarnya menyatakan persentase manusia dalam suatu populasi yang memiliki dimensi tubuh yang sama atau lebih kecil dari nilai tersebut

Perumusan persentil dinyatakan dalam tabel berikut:

Tabel 1. Perhitungan persentil

\begin{tabular}{|c|c|}
\hline PERCENTIL KE- & PERHITUNGAN \\
\hline 1 & $\bar{x}-2,325 \sigma_{x}$ \\
\hline 2,5 & $\bar{x}-1,960 \sigma_{x}$ \\
\hline 5 & $\bar{x}-1,645 \sigma_{x}$ \\
\hline 10 & $\bar{x}-1,280 \sigma_{x}$ \\
\hline 50 & $\bar{x}$ \\
\hline 90 & $\bar{x}+1,280 \sigma_{x}$ \\
\hline 95 & $\bar{x}+1,645 \sigma_{x}$ \\
\hline 97,5 & $\bar{x}+1,960 \sigma_{x}$ \\
\hline 99 & $\bar{x}+2,325 \sigma_{x}$ \\
\hline
\end{tabular}

Keterangan:

$$
\begin{aligned}
\bar{x} & =\text { rata }- \text { rata } \\
\sigma_{x} & =\text { simpangan baku }
\end{aligned}
$$

\section{METODE}

Dalam penelitian ini data yang digunakan untuk perancangan alat adalah data sekunder. Hal ini karena yang akan memanfaatkan alat hanya satu orang. Perancangan alat didasarkan data antropometri orang Indonesia Suku Jawa.

Proses pengambilan data dilakukan dengan memasukkan pakaian yang telah dicuci dan dikeringkan dengan pengering mesin cuci ke dalam lemari pengering. Panas buangan dari AC disalurkan ke dalam lemari pengering. Hal yang sama dilakukan untuk proses pengeringan di luar rumah.

Sebelum proses pengeringan dilakukan massa pakaian ditimbang dan setelah 10 menit pakaian diangkat dan ditimbang kembali. Tujuannya adalah untuk menentukan laju pengurangan kadar air pada pakaian dengan rumus:

$$
\begin{aligned}
& \text { Laju Pengurangan Air }=\frac{m_{i}-m_{f}}{\Delta t} \\
\mathrm{~m}_{\mathrm{i}}= & \text { massa awal } \\
\mathrm{m}_{\mathrm{f}}=\text { massa akhir } & \text { selang waktu }
\end{aligned}
$$

Untuk menentukan efisiensi lemari pengering dibandingkan dengan pengeringan alami. menggunakan rumus:

$$
\text { Efisiensi }=\left|\frac{\text { Laju (lemari) }- \text { Laju (luar) }}{\text { Laju (luar) }}\right| \times 100 \%
$$

Tahapan-tahapan dalam penelitian digambarkan dalam diagram alir berikut ini:

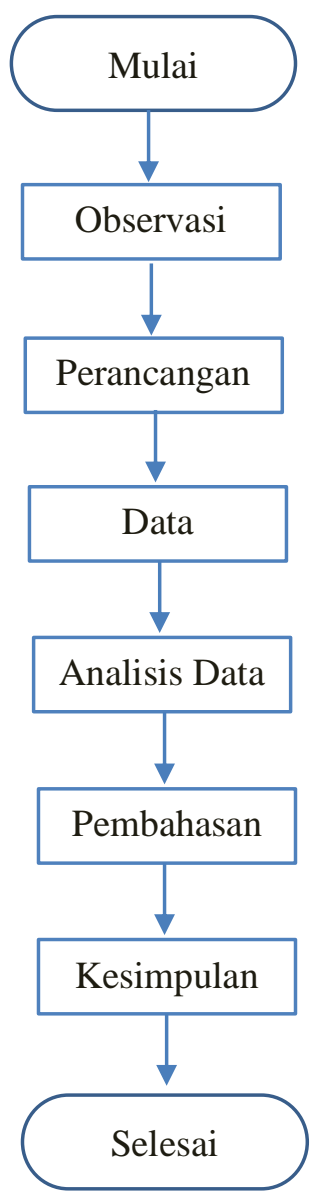

Gambar 2. Diagram Alir Kegiatan 


\section{HASIL DAN PEMBAHASAN}

Untuk menentukan ukuran lemari pengering pakaian, diperlukan data antropometri manusia. Dalam perancangan ini digunakan data antropometri rata-rata orang Indonesia khususnya suku Jawa, karena hasil perancangan ini akan dimanfaatkan oleh pelaku usaha Laundry Si Doel.

Berdasarkan data antropometri orang Indonesia Suku Jawa yang digunakan untuk merancang lemari adalah tinggi siku berdiri (TS), dimana masing-masing memiliki harga sebagai berikut:

Tabel 2. Data tinggi siku berdiri

\begin{tabular}{|c|c|}
\hline Percentile & TS $(\mathrm{cm})$ \\
\hline $5^{\text {th }}$ & 90.2 \\
\hline $50^{\text {th }}$ & 102.92 \\
\hline $95^{\text {th }}$ & 115.64 \\
\hline
\end{tabular}

Perhitungan tinggi lemari dan panjang lemari berdasarkan perumusan sebagai berikut:

Tinggi Lemari $=$ Tinggi Siku (P5) + Faktor Koreksi Sandal

Tinggi siku antropometri Suku Jawa pada persentil ke-5 adalah 90,2 cm dan faktor koreksi sandal $1,5 \mathrm{~cm}$, sehingga:

$$
\begin{aligned}
\text { Tinggi Lemari } & =90,2+1,5=91,7 \mathrm{~cm} \\
& \approx 92 \mathrm{~cm}
\end{aligned}
$$

Sedangkan panjang lemari mengikuti lebar maksimum hanger, yaitu $55 \mathrm{~cm}$ dan lebar lemari menyesuaikan dengan tempat lemari akan diletakkan yaitu $60 \mathrm{~cm}$.

\section{Desain Lemari}

Lemari pengering pakaian didesain secara ergonomis dengan dimensi sebagai berikut:

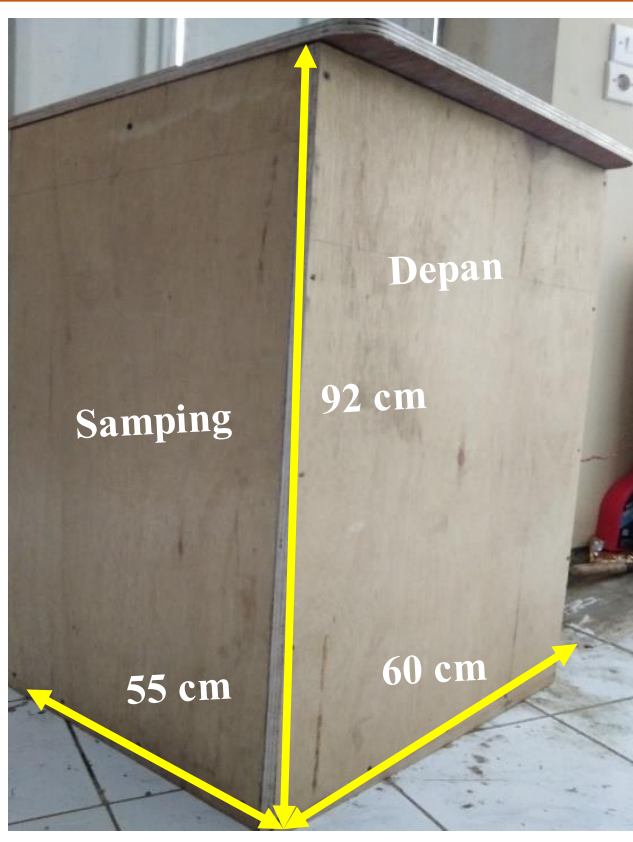

Gambar 3. Dimensi lemari pengering

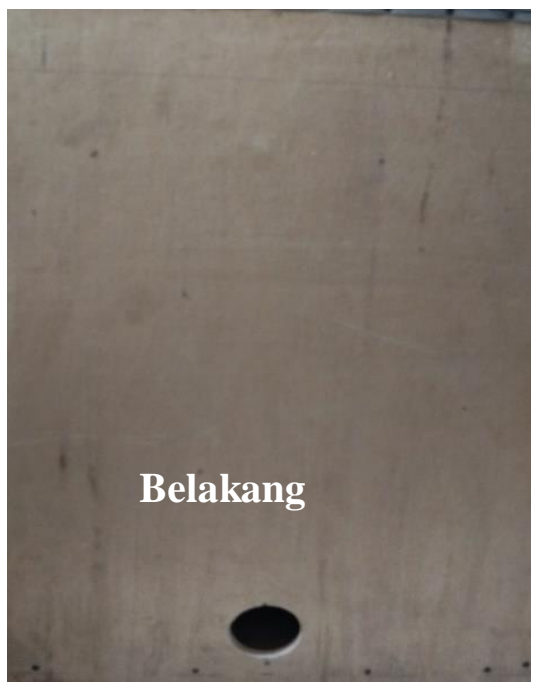

Gambar 4. Lemari pengering tampak belakang

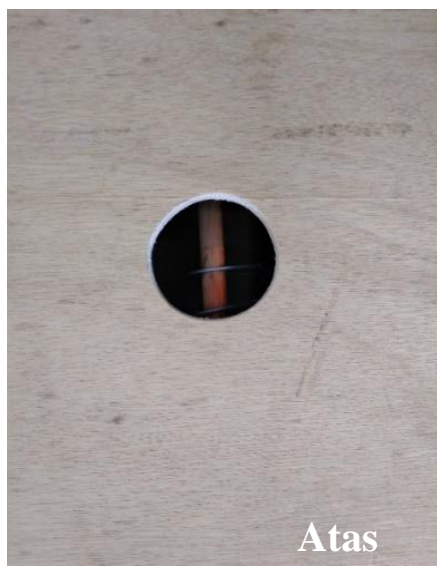

Gambar 5 Lemari pengering tampak atas 


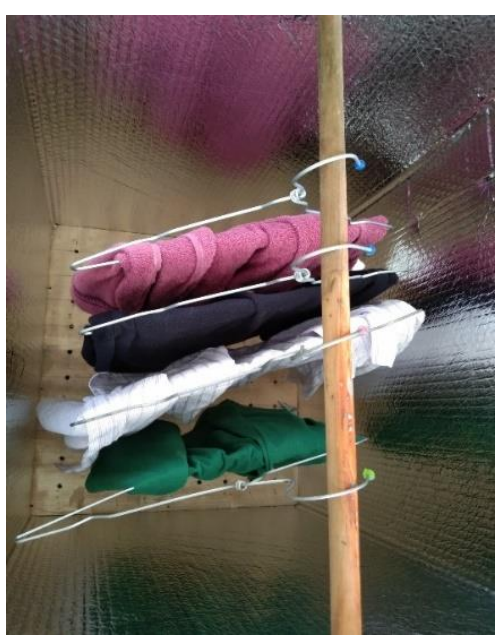

Gambar 6. Posisi pakaian dalam lemari pengering

\section{Gambaran Lemari Pengering}

Pada bagian belakang lemari terdapat lubang yang digunakan untuk saluran panas masuk ke dalam lemari. Di antara lemari dan bagian dasar terdapat sekat yang dilubangi secara merata dengan diameter $1 \mathrm{~cm}$, hal ini bertujuan agar distribusi panas dapat merata di semua pakaian, sedangkan bagian atas terdapat lubang yang berfungsi sebagai pembuangan panas dari dalam lemari, dengan demikian aliran panas dapat ditangkap oleh pakaian sebagaimana angin panas yang menerpa pakaian yang dijemur.

Hasil rancangan diujicoba di Laundry $\mathrm{Si}$ Doel. Hasil uji coba dalam rangka untuk menentukan laju pengurangan kadar air dalam waktu 10 menit ditunjukkan pada tabel 3 berikut ini:

Tabel 3. Data hasil penelitian

\begin{tabular}{|c|c|c|c|c|}
\hline \multirow{2}{*}{ Jenis Kain } & \multicolumn{4}{|c|}{ Massa (gram) } \\
\hline & Awal & Akhir & Awal & Akhir \\
\hline Handuk & 374.4 & 357 & 403.1 & 392.5 \\
\hline Baju & 187.1 & 162.9 & 171 & 162.6 \\
\hline Kaos Tipis & 321.5 & 308.9 & 311.9 & 306 \\
\hline \multirow[t]{2}{*}{ Kaos Tebal } & 231.6 & 216.3 & 231.9 & 225.9 \\
\hline & \multicolumn{2}{|c|}{ Dalam Lemari } & \multicolumn{2}{|c|}{$\begin{array}{l}\text { Di luar rumah } \\
\text { (mendung) }\end{array}$} \\
\hline
\end{tabular}

Berdasarkan data hasil penelitian dapat dihitung laju pengurangan kadar air dalam pakaian yang dijemur dengan rumus:

$$
\begin{aligned}
& \text { Laju Pengurangan Air }=\frac{m_{i}-m_{f}}{\Delta t} \\
& \mathrm{~m}_{\mathrm{i}}=\text { massa awal } \\
& \mathrm{m}_{\mathrm{f}}=\text { massa akhir } \\
& \Delta t=\text { selang waktu }
\end{aligned}
$$

Untuk handuk yang dikeringkan dalam lemari, laju pengurangan kadar air dihitung sebagai berikut:

$$
\begin{aligned}
\text { Laju Pengurangan Air } & =\frac{374,4-357}{10} \\
& =1,74 \mathrm{gr} / \text { menit }
\end{aligned}
$$

Hasil selengkapnya untuk bahan pakaian dan kondisi yang berbeda disajikan pada tabel berikut:

Tabel 4 Laju pengurangan kadar air dalam pakaian

\begin{tabular}{|c|l|c|c|c|}
\hline \multirow{4}{*}{ Pengeringan } & \multirow{2}{*}{$\begin{array}{l}\text { Jenis } \\
\text { Kain }\end{array}$} & \multicolumn{2}{|c|}{ Massa (gram) } & \multicolumn{2}{|c|}{$\begin{array}{c}\text { Laju } \\
\text { Pengurangan } \\
\text { Kadar Air } \\
\text { (gr/menit) }\end{array}$} \\
\cline { 3 - 5 } & & Awal & Akhir & \\
\hline \multirow{4}{*}{$\begin{array}{c}\text { Dalam } \\
\text { lemari }\end{array}$} & Handuk & 374.4 & 357 & 1.74 \\
\cline { 2 - 5 } & Baju & 187.1 & 162.9 & 2.42 \\
\cline { 2 - 5 } & $\begin{array}{l}\text { Kaos } \\
\text { Tipis }\end{array}$ & 321.5 & 308.9 & 1.26 \\
\cline { 2 - 5 } & $\begin{array}{l}\text { Kaos } \\
\text { Tebal }\end{array}$ & 231.6 & 216.3 & 1.53 \\
\hline \multirow{4}{*}{$\begin{array}{c}\text { Di luar } \\
\text { (mumah }\end{array}$} & Handuk & 403.1 & 392.5 & 1.06 \\
\cline { 2 - 5 } & Baju & 171 & 162.6 & 0.84 \\
\cline { 2 - 4 } & $\begin{array}{l}\text { Kaos } \\
\text { Tipis }\end{array}$ & 311.9 & 306 & 0.59 \\
\cline { 2 - 4 } & $\begin{array}{l}\text { Kaos } \\
\text { Tebal }\end{array}$ & 231.9 & 225.9 & 0.6 \\
\hline
\end{tabular}

Penggunaan lemari pengering yang menggunakan sumber panas dari buangan AC cukup efektif dalam proses pengeringan pakaian. Efisiensi hasil proses pengeringan di dalam lemari dibandingkan dengan proses pengeringan di luar rumah (dijemur dalam kondisi mendung), dihitung dengan rumus:

Efisiensi $=\left|\frac{\text { Laju (lemari) }- \text { Laju (luar) }}{\text { Laju (luar) }}\right| \times 100 \%$

Untuk handuk efisiensi lemari diperoleh: Efisiensi $=\left|\frac{1,74-1,06}{1,06}\right| \times 100 \%=64,15 \%$ 
Hasil selengkapnya dapat dilihat pada tabel berikut ini:

Tabel 5 Efisiensi pengeringan pakaian menggunakan lemari dan pengeringan biasa

\begin{tabular}{|l|c|}
\hline \multicolumn{1}{|c|}{ Jenis Kain } & Efisiensi \\
\hline Handuk & $64.15 \%$ \\
\hline Baju & $188.10 \%$ \\
\hline Kaos Tipis & $113.56 \%$ \\
\hline Kaos Tebal & $155.00 \%$ \\
\hline
\end{tabular}

\section{PEMBAHASAN}

Berdasarkan hasil perhitungan jelas bahwa pengeringan pakaian dalam lemari hasil rancangan lebih efisien dari pada pengeringan konvensional di luar rumah dalam kondisi mendung, sehingga lemari ini dapat digunakan sebagai pengering pakaian setelah dicuci, apalagi bila kondisi mendung dan tidak turun hujan suhu ruangan cukup panas, sehingga penggunaan $\mathrm{AC}$ bisa membantu mendinginkan ruangan. Penggunaan AC akan menghasilkan panas yang harus dibuang, panas buangan inilah yang bermanfaat untuk proses pengeringan baju setelah dicuci.

\section{KESIMPULAN DAN SARAN \\ Kesimpulan}

Kabinet pengering pakaian yang dirancang untuk memenuhi kebutuhan proses pengeringan di Laundry Si Doel. Lemari ini cukup efektif dan efisien untuk mengeringkan pakaian yang telah dicuci dan dikeringkan dengan mesin cuci. Alat ini utamanya dapat digunakan ketika kondisi sedang mendung (cuaca berawan), karena berdasarkan fakta efisiensi alat ini sangat besar dibandingkan dengan proses pengeringan konvensional. Dengan rancangan kabinet pengering ini diharapkan produktivitas Laundry Si Doel dapat meningkat secara signifikan.

\section{Saran}

Pada kegiatan ini untuk teknologi kontrol temperatur dan kelembaban belum bisa diterapkan. Hal ini dikarenakan sumber panas yang digunakan adalah $\mathrm{AC}$, dimana selama $\mathrm{AC}$ digunakan untuk mendinginkan ruangan, maka panas yang dihasilkan juga tetap berlangsung dan tidak akan terjadi kebakaran. Untuk kegiatan berikutnya bagi yang akan melakukan seperti kegiatan ini, kontrol temperatur dan kelembaban dapat diaplikasikan dengan menggunakan sumber panas yang lain, seperti hair dryer atau elemen pemanas setrika, dan lain-lain.

\section{DAFTAR PUSTAKA}

Ambarita, Himsar, dkk. 2016. Performance Of A Clothes Drying Kabinet By Utilizing Waste Heat From A Split-Type Residential Air Conditioner. 2214157X/\& 2016 The Authors. Published by Elsevier, Ltd.

Andar, Heryanto. 2018. Pengujian Variasi Massa Pada Lemari Pengering Pakaian Portable Sistem Hibrida Dengan Menggunakan Panas Buang Kondensor AC Split 1 PK. Skripsi. Departemen Teknik Mesin, Fakultas Teknik Universitas Sumatera Utara.

http://repositori.usu.ac.id/bitstream/handl e/123456789/9906/120401153.pdf?seque nce $=1 \&$ is Allowed $=\mathrm{y}$

Muchsin Harianto. 2009. Perancangan Meja Sebagai Alat Bantu Memotong Kain Selimut Di Perusahaan Kapas Putih Klaten. Skripsi. Jurusan Teknik Industri, Fakultas Teknik, Universitas Sebelas Maret. Surakarta.

https://eprints.uns.ac.id/8760/1/14926160 8201002181.pdf

Perhimpunan Ergonomi Indonesia. Data Antropometri, Rekap Data Antropometri Indonesia.

https://antropometriindonesia.org/index.p hp/detail/artikel/4/10/data antropometri

Sumanto, dkk. 2019. Pemanfaatan Kalor Pembuangan AC untuk Pengering Pakaian. Laporan Penelitian, LPPM ITN Malang.

Tarwaka, dkk. 2004. Ergonomi Untuk Keselamatan, Kesehatan Kerja dan Produktivitas. Edisi 1. Uniba Press, Surakarta.

Varman, Mahendra, dkk. 2010. Clothes Drying From Room Air Conditioning Waste Heat: Thermodynamics Investigation. The Arabian Journal for Science and Engineering, Volume 35, Number 1B. 
Yacobus, Damar Alit. 2016. Mesin Pengering Pakaian Sistem Tertutup Dengan menggunakan Energi Listrik 1711 Watt. Skripsi. Program Studi Teknik Mesin, Jurusan Teknik Mesin, Fakultas Sains dan Teknologi, Universitas Sanata Dharma, Yogjakarta. http://repository.usd.ac.id/30495/2/11521 4035_full\%5B1\%5D.pdf https://digilib.esaunggul.ac.id/public/UEUpaper-6680-04 antropometri 1 -1.pdf http://repository.maranatha.edu/4297/ 2/0023067 Appendices.pdf 